\title{
Violência sexual: procedimentos indicados e seus resultados no atendimento de urgência de mulheres vitimas de estupro
}

\author{
Sexual violence: Recommended procedures and results of emergency care for women victims of rape
}

\author{
Aníbal Faúndes ${ }^{1}$, Cristião Fernando Rosas², Aloísio José Bedone ${ }^{3}$, Luis Távara Orozco ${ }^{4}$
}

\section{RESUMO}

Violência sexual contra a mulher é uma das expressões da violência baseada no gênero, que tem como origem o desequilíbrio de poder existente entre homens e mulheres, com maior ou menor intensidade, em todos os países do mundo. Atualmente é reconhecida como um problema de direitos humanos pela ONU, incluindo a violência emocional, física e sexual. A prevalência de violência sexual é muito difícil de determinar, mas provavelmente afeta pelo menos um terço das mulheres alguma vez na vida. Tem variadas conseqüências sobre a saúde física, mental e ginecológica da mulher, as que dependem em grande parte do atendimento recebido logo após a violência. Infelizmente, a maior parte dos serviços de emergência não estão preparados para prestar atendimento adequado. $\mathrm{O}$ atendimento deve ser multidisciplinar e incluir anamnese e exame clínico cuidadosos utilizando exames laboratoriais, tratamento das lesões físicas e da crise emocional, prevenção da gravidez e de doenças de transmissão sexual, incluídos HIV/AIDS e com seguimento de pelo menos seis meses.

PALAVRAS-CHAVE: Violência sexual; Agressão; Estupro; Violência; Mulheres maltratadas

\section{ABSTRACT}

Gender-based violence is related to the power imbalance between men and women that is present, to a greater or lesser degree, in all societies. It was recognized as a human rights problem by the UN relatively recently. It includes emotional, physical and sexual violence. Sexual violence is the extreme form of gender violence, usually accompanied by the other types of violence. Its prevalence is difficult to determine, but it most probably affects at least one third of women some time in their life. It has multiple consequences to women's physical and gynecological health, which depends in great part on the quality of the care the woman received immediately after the assault. Unfortunately, most emergency health services, including those in women's hospitals, are rarely prepared to provide the correct care for these women. Care should be multidisciplinary and involves crisis treatment, meticulous clinical examination with complementary auxiliary methods, treatment of physical lesions, prevention of pregnancy and of sexually transmitted infections and AIDS, and follow-up for at least six months after the aggression.

KEYWORDS: Sexual violence; Agression; Sexual abuse; Rape; Violence; Battered women

\section{Introdução}

O direito a uma vida sexual satisfatória livre de violência, coerção ou risco de gravidez não desejada e de adquirir doença é um dos direitos sexuais e reprodutivos mais básicos da mulher. A Organização das

1 Professor Titular Colaborador Voluntário - Departamento de Tocoginecologia - Faculdade de Ciências Médicas - UNICAMP; Pesquisador Sênior - Centro de Pesquisas em Saúde Reprodutiva de Campinas (Cemicamp) - Campinas (SP), Brasil.

2 Médico Assistente do Hospital e Maternidade Escola Dr. Mário Moraes de Altenfelder Silva - Vila Nova Cachoeirinha; Médico Preceptor e Responsável pelos Ambulatórios de perda gestacional de repetição e de Violência Sexual do Hospital e Maternidade Leonor Mendes de Barros

3 Professor Associado da Divisão de Ginecologia do Departamento de Tocoginecologia/CAISM /FCM/UNICAMP; Responsável pelo Programa de atendimento à mulher vítima de violência sexual do Centro de Atenção Integral à Saúde da Mulher (CAISM)

4 Presidente del Comité de Derechos Sexuales y Reproductivos de la Sociedad Peruana de Obstetricia y Ginecología; Coordinador del Comité de Derechos Sexuales y Reproductivos de la Federación Latinoamericana de Sociedades de Obstetricia y Ginecología; Director Médico del Centro de Promoción y Defensa de los Derechos Sexuales y Reproductivos, Perú

Correspondência: Aníbal Faúndes

Cemicamp - Caixa Postal 6181 - 13.084-971 - Campinas - SP - Telefone: (19) 3289-2856 - Fax: (19) 3289-2440 - e-mail: afaundes@unicamp.br 
Nações Unidas (ONU) define violência de gênero como "qualquer ato de violência baseado no gênero que resulte ou possa resultar em dano ou sofrimento físico, sexual ou psicológico a uma mulher, incluindo ameaça de tais atos, coerção, privação arbitrária da liberdade, seja no âmbito público ou

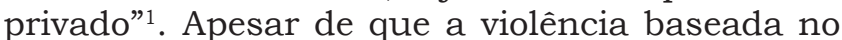
gênero pode afetar também os homens, na imensa maioria dos casos a vítima é uma mulher e o agressor é um homem².

A violência baseada no gênero sempre existiu, mas só recentemente está sendo discutida no Brasil e no resto do mundo. O reconhecimento público do problema tem levado a propor soluções que têm recebido apoio internacional, particularmente nas Conferências do Cairo (1994) e Beijing $(1995)^{3-7}$.

A aceitação social da violência baseada no gênero, no interior da família e fora dela, faz com que a mulher não a denuncie, levando a um desconhecimento da real prevalência desta ocorrência. Entretanto, as informações disponiveis sugerem que milhões de mulheres estão sofrendo este tipo de violência e vivendo as suas conseqüências ${ }^{8}$.

Apesar de sua alta freqüência e das sérias implicações sobre a saúde da vítima, a violência sexual continua sendo ignorada e não é componente habitual dos programas de saúde sexual e reprodutiva, inclusive em faculdades de medicina no Brasil. A necessidade de prestar urgente atenção a este problema se justifica, não apenas por representar séria violação dos direitos humanos das vítimas, mas porque um atendimento de emergência adequado pode prevenir grande parte das conseqüências dessa violência. Ginecologistas e obstetras precisam estar mais bem informados sobre este tema. Enquanto não souberem avaliar a importância dos sintomas e sinais apresentados pelas mulheres que sofrem este tipo de violência, e prevenir e tratar as suas conseqüências, não poderão identificar o problema nem dar o atendimento que suas pacientes esperam deles.

\section{Prevalência}

Não é possível avaliar a prevalência da violência sexual a partir das estatísticas da polícia ou de serviços de saúde que atendem estes casos, porque apenas pequena parte das mulheres agredidas denuncia o fato ou procura atendimento ${ }^{9}$. Dados mais reais se obtêm por meio de inquéritos populacionais, mas estes mostram enorme variabilidade entre diferentes estudos. Esta variabilidade é causada tanto pelas diferenças entre as populações estudadas como pelas distintas definições de violência sexual. Por exemplo, para muitas mulheres a violência praticada pelo seu parceiro não é considerada estupro, aceitando as normas sociais que atribuem ao homem o direito de usar do corpo da mulher ao seu arbitrio ${ }^{10}$.

Levando em consideração estas limitações, revisão dos diferentes estudos em vários países desenvolvidos e não desenvolvidos do mundo indica que entre 10 e $35 \%$ das mulheres são vítimas de violência sexual alguma vez na sua vida ${ }^{3-5,10-21}$.

A maior parte dos estudos, entretanto, avalia a prevalência de violência sexual em mulheres de 15 a 49 anos, o que significa que há uma mistura de mulheres com pouco tempo de exposição ao risco de ter sido violentada e outras no fim de sua vida reprodutiva. Como a possibilidade de sofrer violência sexual alguma vez na vida vai se somando à medida que passam os anos, a prevalência deste tipo de violência alguma vez na vida é necessariamente mais alta que a média que inclui mulheres jovens e de mais idade nos estudos publicados.

Em resumo, pode-se afirmar que pelo menos uma de cada três mulheres sofre violência sexual ao menos uma vez durante sua vida ${ }^{9,22,23}$.

\section{Característica da violência sexual}

Apesar de que qualquer mulher pode ser vítima de violência sexual em qualquer momento, há evidências de que as mulheres mais jovens e as adolescentes têm mais risco de sofrer este tipo de violência, especialmente se elas vivem com somente um dos pais ou com padrasto ${ }^{17}$. Entre as adolescentes, é freqüente que sua primeira relação sexual tenha ocorrido sob o uso de força ou coerção, particularmente naquelas que iniciam sua vida sexual mais precocemente ${ }^{20,24,25}$.

Mulheres com história de terem sido oprimidas ou molestadas sexualmente durante a infância têm mais probabilidades de serem estupradas durante a adolescência ou idade adulta ${ }^{14,17,26}$. Do mesmo modo, o uso de álcool ou de drogas aumenta o risco de serem estupradas ${ }^{17,18,26,27}$. A identidade do agressor é diferente em estatísticas da polícia ou de serviços de saúde quando comparadas com estudos de população. Nas primeiras há franco predomínio de desconhecidos, ao passo que nos segundos, na grande maioria das vezes, os agressores são conhecidos ou membros da família ${ }^{28-30}$. Esta diferença mostra que quando o agressor é pessoa próxima à mulher agredida ela se inibe em denunciar a violência e em pedir ajuda nos serviços de saúde. A falta de denúncia e solicitação de ajuda nos serviços de saúde é um dos motivos pelos quais os profissionais de saúde não percebem a alta prevalência do problema nem 
sua relação com a saúde sexual e reprodutiva das mulheres. Precisamos estar mais alertas, ter uma escuta qualificada e identificar os sintomas e sinais de violência sexuais entre nossas pacientes.

\section{Consequêencias da violência sexual sobre a saúde das mulheres}

As conseqüências da violência sexual podem ser imediatas e de longo prazo e podem ser fisicas e psicológicas $^{31}$. O trauma físico genital ou de outras partes do corpo pode ou não estar presente, porque quando o agressor usa uma arma ou é muito mais forte que a vítima, esta não tem condições de opor resistência. As lesões genitais se observam com mais freqüências nas crianças e nas mulheres de maior idade, podendo incluir lacerações, hematomas, equimoses e edema, afetando os lábios menores, o hímen e a fossa navicular. No caso de agressão sexual a crianças, as lesões podem incluir lesões na vagina, períneo, ânus e reto ${ }^{31-38}$.

A freqüência de gravidez não desejada após estupro é imprecisa ${ }^{39}$. Um estudo a estima entre 10 e $30 \%{ }^{40}$, porém os dados mais fidedignos provêm de um estudo prospectivo de uma amostra representativa de mais de 4000 mulheres de 18 anos ou mais seguidas por um período de três $\operatorname{anos}^{41}$. Neste estudo se encontrou taxa de gravidez de $5 \%$ por episódio de estupro, o que provavelmente é o limite inferior do risco de engravidar, porque esse estudo incluía poucas adolescentes, que podem ter maior probabilidade de ficar grávidas que mulheres de maior idade. Em estudo entre adolescentes estupradas na Etiópia, por exemplo, foi relatado que $17 \%$ delas engravidaram ${ }^{42}$.

A gravidez resultante de estupro é quase sempre extremamente rejeitada pela mulher e, portanto, freqüentemente termina em aborto. Isto pode ter poucas conseqüências para a saúde em países onde o aborto é legal e os serviços de qualidade são de fácil acesso, mas pode ter graves conseqüências nos países com leis restritivas em que o aborto seguro não é acessivel, ainda naqueles casos previstos na lei, como acontece até hoje no Brasil. Dada a rejeição absoluta da gravidez por parte da maioria das grávidas por estupro, elas precisam recorrer ao aborto clandestino, que será de risco para aquelas com poucos meios econômicos, expondo-as desnecessariamente a complicações graves e à morte ${ }^{31,39}$. No Brasil, assim como em muitos outros países em que a lei permite o aborto de gravidez resultado de estupro, essa lei não é aplicada devido a barreiras médicas e administrativas ${ }^{43}$. A experiência mostra que a atitude preconceituosa dos profissionais de saúde desestimula as mulheres a solicitar atendimento e restringe o acesso ao aborto legal e seguro. Obstetras e ginecologistas têm papel fundamental em derrubar essas barreiras e facilitar o acesso ao aborto legal em hospitais públicos ${ }^{43-45}$.

Estima-se que o risco de adquirir uma doença sexualmente transmissivel (DST) seja de 4 a $30 \%$, tanto em países desenvolvidos como menos desenvolvidos ${ }^{32,40,46-49}$. As taxas variam para cada agente específico e segundo a faixa etária. A taxa de infecção por Neisseria gonorrhoeae pode variar entre 0,8 e 9,6\%, de 3,1 a $22 \%$ para Trichomonas vaginallis, de 1,5 a $26 \%$ para Chlamydia trachomatis, entre 12 a $50 \%$ para vaginose bacteriana, de 2 a $40 \%$ para o papiloma virus humano (HPV), de até $1,6 \%$ para o Treponema pallidum e de 3\% para a hepatite B. Quando não são prevenidas ou tratadas precocemente, essas infecções podem levar a sérias complicações a longo prazo (doença inflamatória pélvica, esterilidade de causa tubária, gravidez ectópica, dor pélvica crônica). Justifica-se, portanto, que muitas destas mulheres demonstrem preocupação com a possibilidade de se infectar com alguma DST, particularmente pelo HIV ${ }^{50-52}$.

A transmissão sexual do HIV está bem estabelecida, assim como o maior risco associado ao sexo anal. O risco aumenta ainda mais se a agressão provoca feridas na região genital ou anal, como acontece freqüentemente na violência sexual contra crianças e adolescentes ${ }^{31,53-56}$.

As conseqüências psicológicas são muito variáveis, já que cada mulher responde de forma diferente à violência sexual. Diversos transtornos psicológicos são descritos nestas mulheres, incluindo depressão, fobias, ansiedade, uso de drogas ilícitas, tentativa de suicídio e as chamadas síndrome de estresse pós-traumático ${ }^{23,31,57,58}$ ou síndrome do trauma do estupro ${ }^{23,31,57,59}$.

Apesar de que a sindrome de estresse póstraumático e a síndrome do trauma do estupro são relativamente pouco freqüentes, outras seqüelas psicológicas se observam com muita freqüência e podem expressar-se de muitas formas: cefaléia crônica, fadiga, transtornos do sono, pesadelos e transtornos da apetite ${ }^{60-62}$. Vários estudos têm mostrado, ainda, que mulheres com história de violência sexual têm maior incidência de alterações menstruais, dor pélvica crônica, dispareunia e disfunções sexuais que aquelas que nunca sofreram esse tipo de violência ${ }^{10,31,63-66}$.

\section{Atendimento às vitimas de violência sexual}

Nos dias de hoje, na maior parte do mundo, o cuidado das mulheres que sofrem violência se- 
xual fica como responsabilidade da polícia ou de serviços de emergência que habitualmente não estão preparados para responder às necessidades destas mulheres. Mais grave ainda é a atitude enviesada dos provedores de serviços de saúde e da polícia, que tendem a culpar a vítima, desestimulando as mulheres violentadas a pedir ajuda ou denunciar o agressor. Infelizmente são priorizadas as necessidades da justiça de identificar e perseguir o agressor, em relação às necessidades da mulher violentada. Conseqüentemente $\mathrm{o}$ atendimento muitas vezes se limita à coleta de amostras para identificação de DNA e ao tratamento de eventuais traumas sofridos pela mulher.

Dada as múltiplas conseqüências da violência sexual, o atendimento à vítima requer a participação de uma equipe multidisciplinar. Além disso, muitas vezes membros das famílias também precisam de atendimento psicológico e social, além da mulher ou criança agredida. É claro que esse escopo tão amplo vai além da especialidade tocoginecológica, porém o médico tem papel de liderança na organização dos serviços e em influenciar os governos para comprometerem-se a proporcionar atendimento integral às mulheres que sofrem violência sexual.

Um principio fundamental é que o atendimento não pode limitar-se à emergência, visto que a violência sexual tem conseqüências em longo prazo que devem ser prevenidas e tratadas quando aparecerem. O seguimento, portanto, não deve ser menor que seis meses, tal como se descreve a seguir.

\section{Atendimento de emergência à mulher que sofre violência sexual}

\section{Recepção}

A mulher estuprada ou agredida sexualmente precisa de atendimento rápido para cuidar da crise emocional que ela sofre, assegurando-lhe privacidade e uma atitude respeitosa, sensivel e solidária $^{23,31,67-70}$. Funcionárias(os) da recepção devem ser treinados para dar prioridade a estes casos e para encaminhá-las a local separado onde não possam ser identificadas como "a mulher que foi estuprada". O(a) profissional responsável pelo atendimento destes casos deve ser avisado de imediato para que o atendimento seja o mais rápido possivel.

O pessoal de saúde tem que estar muito alerta e entender que, imediatamente após uma violência sexual, a mulher está precisando desesperadamente de apoio emocional; sua auto-estima e seu ego podem ter sido feridos com mais gravidade que qualquer lesão fisica que possa apresentar. Portanto, ela precisa de uma pessoa que mostre simpatia e compreensão, disposta a escutar com respeito e interesse e preparada para dar apoio emocional.

Os serviços de emergência geralmente não possuem psicólogos formados como parte da equipe, mas nesse momento, mais importante que um psicólogo profissional, é a atitude respeitosa e de apoio da pessoa que dá o primeiro atendimento. Esse profissional pode ser um médico, mas também pode ser uma enfermeira ou uma assistente social. Como as enfermeiras formam parte habitual destas equipes, o mais freqüente é que essas profissionais sejam as que são treinadas para dar este primeiro atendimento às mulheres que sofrem violência sexual.

É preciso lembrar que os provedores de serviços de saúde também podem ter sido vítimas de violência ou ainda podem ter sido agressores. Portanto, nem todos os membros da equipe terão condições de prestar este tipo de atendimento e só aqueles adequadamente treinados devem ser alocados para cumprir esta função. Cuidar de mulheres que sofreram agressão sexual não é tarefa fácil e muitas vezes as pessoas que dão assistência também precisam de apoio psicológico pelo impacto das histórias que têm que escutar. Portanto, as pessoas responsáveis por estes cuidados devem ser criteriosamente selecionadas e só aquelas que voluntariamente se ofereçam para participar no treinamento e mostrem aptidão devem fazer parte da equipe.

As vitimas da violência sexual esperam mais que a simples aplicação de protocolos. Esperam receber um atendimento digno, respeitoso e acolhedor, que as protejam da revitimização. Cabe ao médico e demais profissionais de saúde o reconhecimento de seu importante papel, com um exercício ético e responsável de medidas protetoras de sua saúde e de seus direitos humanos ${ }^{71}$.

\section{Anamnese}

As pessoas especialmente treinadas irão acolher estas mulheres, escutar suas histórias e documentá-las detalhadamente no prontuário. Usuárias destes serviços, geralmente muito gratas pelo atendimento recebido, informam, entretanto, que sentem como uma nova agressão ter que repetir a mesma história a diversas pessoas, fazendo-as reviver a horrivel experiência que quiseram esquecer o mais rapidamente possivel ${ }^{72}$. Recomenda-se, portanto, que a primeira pessoa que escuta a história faça uma descrição detalhada da violência, incluindo o tipo ou tipos de agressão, número de agressores e a hora e o dia da agressão. Neste sentido, recomenda-se a adoção de ficha única a ser utilizada por todos os profissionais que atendem a mulher (enfermeira, médico, assistente social e psicóloga). Com este procedimento, evita-se que os 
diferentes membros da equipe perguntem novamente detalhes da violência sofrida.

É importante usar a próprias palavras da vítima e sem atribuir nenhum juízo referente à aparência ou ao comportamento da mulher, que pode ser usado contra ela em eventual procedimento judicial posterior. Depois de controlada a crise emocional se deve obter consentimento para o exame físico e ginecológico.

\section{O exame físico}

O exame físico tem o duplo propósito de obter as provas de que precisa o sistema judicial e identificar as lesões que requerem tratamento. Deve ser realizado pelo profissional melhor preparado disponivel no plantão, que deve documentar cuidadosamente seus achados. Nunca deve ser realizado sem a presença de outra pessoa, que pode ser uma enfermeira ou uma outra mulher da família que esteja acompanhando a vitima.

$\mathrm{O}$ exame deve incluir o estado geral e sinais vitais, exame dos membros na procura de traumas, inspeção da face e couro cabeludo, pescoço, tronco e mamas. Com a paciente em decúbito dorsal examinar o abdome, pernas, face interna das coxas e as nádegas.

Realizar a seguir o exame ginecológico e anal para identificar eventuais traumas nos genitais externos e no ânus. A seguir realizar exame ginecológico especular e digital na vagina e no cérvix. Realizar exame retal somente se indicado, incluindo nesse caso a proctoscopia, se for necessário $^{37,73}$. Anotar e classificar cuidadosamente todas as lesões traumáticas identificadas. Colher amostras que possam identificar o agressor, tais como pêlos, cabelo, unhas, sangue, sêmen, fragmentos de pele (nas unhas da vitima) ${ }^{23,31,67-70}$.

A coleta adequada do material do agressor é importante para posterior condenação do culpado. O ideal é que este procedimento seja realizado no IML. Se isto não for possivel, a recomendação do Ministério da Saúde é que a colheita seja feita por meio de swab ou similar e o material seja colocado (após secar em temperatura ambiente) em envelope lacrado. O envelope deve ser guardado em ambiente climatizado ou, idealmente, em freezer, de acordo com as condições de cada serviço. É imperioso garantir a cadeia de custódia, ou seja, sempre que o material for encaminhado, deve-se fazer o registro pertinente ${ }^{67}$.

\section{Exames Complementares}

Testes laboratoriais para sifilis, hepatite B e C, HIV, Chlamydia, gonorréia, Trichomonas e HPV e para o de diagnóstico de gravidez devem ser feitos na admissão e serem repetidos posteriormente durante o seguimento. Ocasionalmente podem estar indicados exames radiográficos, tomografia ou ultra-sonografia.

\section{Tratamento}

Deve incluir o tratamento das lesões fisicas que possam estar presentes e a prevenção de gravidez e de doenças de transmissão sexual. É preciso, também, oferecer tratamento psicológico a estas mulheres pelo tempo que for necessário. Por isso mesmo é preciso ter disponivel um serviço de psicologia para onde referir estas pacientes com segurança. Lesões físicas podem estar presentes com maior freqüência na região genital e anal, sobretudo se a vítima é uma criança ou adolescente jovem. Essas lesões podem requerer sutura, antibióticos, analgésicos e soro e vacina contra o tétano.

A prevenção da gravidez se faz com o uso de anticoncepção de emergência (AE) na forma da administração de 1,5 mg de levonorgestrel, preferentemente em dose única, ou em duas doses de 0,75 mg com 12 horas de intervalo. Se o produto específico não estiver disponivel, pode-se utilizar o método de Yuzpe, que consiste na administração de dois comprimidos de pílula anticoncepcional oral combinada que contenha $250 \mu \mathrm{g}$ de levonorgestrel e etinilestradiol na dose mais baixa disponivel. Essa mesma dose deve ser repetida 12 horas depois $^{74-76}$. Apesar de que existem evidências de que a $\mathrm{AE}$ com levonorgestrel (sem estrógeno) pode ter alguma efetividade até o quinto dia após a violência, maior eficácia é obtida quando administrada nas primeiras 24 horas, pelo que sempre deve se administrar a AE tão logo como possivel.

A quimioprofilaxia das infecções de transmissão sexual deve visar os agentes infecciosos mais prevalentes, de repercussão clínica importante, e está indicada nestas situações independentemente da gravidade das lesões, sexo ou idade da vítima. O Ministério da Saúde do Brasil normatizou, em 2005, as recomendações de prevenção da sífilis, gonorréia, clamidiose, cancro mole, tricomoníase, hepatite B e do HIV, em esquema de associação de medicamentos ${ }^{7,23,31,32,36,56,67,77,78}$.

\section{Profilaxia das DST não virais}

Dentre as recomendações, deverão receber a profilaxia para DST não virais as mulheres ou crianças expostas ao sêmem e/ou outros fluídos do agressor, com exceção dos casos em que o agressor tenha feito uso de preservativo. A profilaxia está indicada nos casos de coito anal, vaginal ou oral, mesmo que não tenha havido ejaculação. Recomenda-se a prescrição dos medicamentos em regime de dose única, o mais pre- 
cocemente possivel, não havendo, com exatidão, tempo limite para a introdução da profilaxia contra DST de natureza não viral, diferente da prevenção pelo HIV. O esquema profilático para DST não virais encontra-se no Quadro 1.

Quadro 1 - Profilaxia das DST não virais em mulheres vítimas de estupro (adultas e adolescentes com mais de $45 \mathrm{~kg}$, não gestantes).

\begin{tabular}{|lccc|}
\hline $\begin{array}{l}\text { Penicilina G benzatina } \\
\text { Profilaxia da sífilis }\end{array}$ & $\begin{array}{c}2,4 \text { milhões UI } \\
(1,2 \text { milhões UI } \\
\text { em cada nádega })\end{array}$ & Dose única \\
$\begin{array}{l}\text { Ofloxacina } \\
\text { Profilaxia da gonorréia }\end{array}$ & $400 \mathrm{mg}$ & VO & Dose única \\
$\begin{array}{l}\text { Azitromicina } \\
\text { Profilaxia da clamidiose e } \\
\text { do cancro mole }\end{array}$ & $1 \mathrm{~g}$ & VO & Dose única \\
$\begin{array}{l}\text { Metronidazol } \\
\text { Profilaxia da tricomoníase }\end{array}$ & $2 \mathrm{~g}$ & VO & Dose única \\
\hline
\end{tabular}

Fonte: Norma Técnica: prevenção e tratamento dos agravos resultantes da violência sexual contra mulheres e adolescentes - Ministério da Saúde/ Brasil - 2005.

O uso de metronidazol e de suas alternativas deve ser evitado no primeiro trimestre da gravidez. As mulheres que estão amamentando devem suspender a amamentação por 24 horas após a ingestão do medicamento. O tianfenicol é contra-indicado em todo período gestacional. Visando a proteção fetal, nos casos de gestantes vitimadas sexualmente recomenda-se a associação dos medicamentos indicados no Quadro 2.

Quadro 2 - Profilaxia das DST não virais em crianças, adolescentes e gestantes vítimas de estupro com menos de $45 \mathrm{~kg}$.

\begin{tabular}{|c|c|c|}
\hline \\
\hline & \\
\hline \multicolumn{3}{|c|}{$\begin{array}{l}\text { Crianças e adolescentes (dose máxima: } 2,4 \text { milhões UI) } \\
\text { Gestantes } \\
50 \text { mil Ul/kg } \\
2,4 \text { milhões UI } \\
\text { (1,2 milhões em cada nádega) }\end{array}$} \\
\hline \multicolumn{3}{|l|}{ Ceftriaxona } \\
\hline \multicolumn{2}{|l|}{$\begin{array}{l}\text { Crianças e adolescentes } \\
\text { Gestantes } \\
\text { Azitromicina }\end{array}$} & IM Dose única \\
\hline \multicolumn{3}{|l|}{ Azitromicina } \\
\hline $\begin{array}{l}\text { Crianças e adolescentes } \\
\text { Gestantes }\end{array}$ & $\begin{array}{l}20 \mathrm{mg} / \mathrm{kg} \\
1 \mathrm{~g}\end{array}$ & VO Dose única \\
\hline \multicolumn{3}{|l|}{ Metronidazol } \\
\hline $\begin{array}{l}\text { Crianças e adolescentes } \\
\text { Gestantes }\end{array}$ & $\begin{array}{c}15 \mathrm{mg} / \mathrm{kg} / \mathrm{dia} \\
2 \mathrm{~g}\end{array}$ & $\begin{array}{l}\text { VO } 8 / 8 \text { horas, } \\
\text { por } 7 \text { dias } \\
\text { (máximo: } 2 \mathrm{~g} \text { ) } \\
\text { Dose única }\end{array}$ \\
\hline
\end{tabular}

Fonte: Norma Técnica: prevenção e tratamento dos agravos da violência sexual contra mulheres e adolescentes - Ministério da Saúde/Brasil - 2005.

As drogas de primeira escolha no Quadro $1 \mathrm{e}$ 2 poderão ser substituídas por alternativas em caso de contra-indicação ao uso ou de hipersensibilidade comprovada, como a seguir indicado: para pro- filaxia da sífilis, a penicilina benzatina pode ser substituída por estearato de eritromicina em doses indicadas ao peso por 15 dias. Contra gonorréia a ofloxacina poderá ser substituída pelo ceftriaxona, ou no caso de mulheres adultas não gestantes, pelo tianfenicol. Contra a clamidiose, o esterarato de eritromicina ou amoxicilina é alternativa à azitromicina, e para o cancro mole a ceftriaxona também é uma opção, e ainda o secnidazol ou tinidazol em substituição ao metronidazol ${ }^{67}$.

\section{Profilaxia das DST Virais}

\section{Profilaxia para a hepatite $B$}

Recomenda-se que recebam esta prevenção as pacientes expostas ao sêmem e/ou outros fluídos corporais do agressor, mesmo na ausência de penetração, sendo excluídas de profilaxia as pacientes vitimadas em que o agressor tenha feito uso de preservativo. Deverão ainda receber a profilaxia as mulheres submetidas ao coito vaginal, anal e/ou oral, bem como quando houver desconhecimento ou dúvida sobre o status vacinal da mulher, situação freqüentemente observada. Nestes casos, a imunização ativa deverá ser instituída com a vacina anti-hepatite $\mathrm{B}$, na dose recomendada pelo fabricante, em injeção intramuscular no deltóide, em três doses com periodicidade 0,1 mês e 6 meses após a violência sexual.

O Programa Nacional de Hepatites Virais (PNHV) recomenda ainda que todas as mulheres vitimadas sexualmente não imunizadas ou com esquema vacinal incompleto devam receber a imunização passiva, por meio da administração de dose única de imunoglobulina hiperimune para hepatite B (IGHAHB), 0,06 mL/kg, intramuscular, em sítio de aplicação diferente da vacina e, se a dose ultrapassar $5 \mathrm{~mL}$, deve-se dividir a aplicação em duas áreas corporais diferentes, até no máximo 14 dias após a violência sexual. Ressalte-se que mesmo em gestantes em qualquer idade gestacional não há contra-indicação para a imunização ativa ou passiva para hepatite B. Não deverão receber a imunoprofilaxia para hepatite $\mathrm{B}$ mulheres em situação de violência sexual crônica e repetida pelo mesmo agressor, situação freqüente em casos de violência familiar ${ }^{67}$.

\section{Profilaxia para o HIV}

Apesar de ainda haver algumas dúvidas quanto à efetividade da profilaxia contra HIV, recomenda-se seu uso, devendo ser administrada até 72 horas após a agressão ${ }^{79}$. O risco de transmissão do HIV depende da gravidade das lesões, 
do tipo de ato sexual forçado, número de agressores e, obviamente, de que um agressor ou mais sejam portadores do vírus. A recomendação da profilaxia anti-HIV baseia-se na experiência com exposição ocupacional à infecção, que mostra que o tratamento reduz o risco de soroconversão em $81 \%$ se administrado em torno de 4 horas após a exposição ${ }^{80}$.

É de fundamental importância informar claramente à mulher sobre seu risco, assim como sobre os efeitos secundários desagradáveis dos anti-retrovirais e da necessidade de completar os 28 dias de tratamento. Somente aquelas que aceitam o tratamento depois de ter recebido essa orientação devem ser incluídas na profilaxia anti HIV $^{19,23,56,67,68,81-83}$.

Dois inibidores do nucleosídeo transcriptase reversa e um inibidor da protease devem ser usados para a profilaxia ${ }^{84}$. O Ministério da Saúde recomenda o seguinte: zidovudina $300 \mathrm{mg}$ oral cada 12 horas + lamivudina $150 \mathrm{mg}$ oral cada 12 horas + indinavir $800 \mathrm{mg}$ oral cada 8 horas, ou nelfinavir $750 \mathrm{mg}$ a cada 8 horas. Esta dose é reduzida em caso de criança ou adolescentes menores ${ }^{67}$.

\section{Seguimento}

Recomenda-se o seguimento após 7 dias e ao final das quatro semanas para verificar que se complete a terapia. Sorologia para sifilis deve ser realizada aos 30 dias, para hepatite $\mathrm{B}$ aos 180 dias e para HIV aos 40, 90 e 180 dias $^{67,68}$.

Outro componente importante do seguimento é o diagnóstico de uma possivel gravidez, se há atraso na menstruação $0^{23,68}$. Confirmada a gravidez, serviços seguros de interrupção da gravidez devem ser oferecidos para a livre decisão da mulher, sem colocar obstáculos burocráticos que limitem seus direitos ${ }^{23,67,68}$.

\section{Encaminhamento para apoio psicológico, social e legal}

Apesar de o apoio psicológico e social não ser da responsabilidade dos serviços de ginecologia e obstetrícia, o atendimento da mulher que sofre violência sexual não seria adequado se não se encaminhar a vítima a estes serviços. A necessidade de apoio psicológico já foi descrita acima. O apoio social é mais urgente quando o agressor é um membro da família e mais ainda se é o arrimo econômico da família.

Quando se trata de menores de 18 anos, o serviço de saúde deve comunicar o fato ao Conselho Tutelar ou à Vara da Infância e Juventude, de acordo com a legislação vigente, e desde 2003, é compulsória a notificação dos casos de violência contra a mulher atendidos na rede pública ou privada.

As mulheres devem ser informadas de seus direitos legais de denunciar criminalmente o agressor e do processo necessário para tanto, assim como os possiveis resultados de tal denúncia. As mulheres também precisam ser plenamente informadas de seu direito legal de interromper a gestação caso engravide como resultado do estupro $^{23,67}$. Para os serviços que se dispõem a prestar atendimento, recomenda-se a divulgação da norma técnica do Ministério da Saúde de 2.005 e da Portaria MS/GM No 1.508/2005, treinamento, fortalecimento e integração das equipes e a criação de protocolos de atendimento que incluam as ações preventivas e o acompanhamento médico e psicológico das mulheres. Bom entrosamento entre as unidades de saúde, as delegacias de polícia, o Instituto Médico-Legal, os Conselhos Tutelares e as ONGs é fundamental.

\section{Conclusão}

A violência sexual contra a mulher é um dos problemas que afetam a mulher mais negligenciados na prática gineco-obstétrica, em grande parte por desconhecimento de sua freqüência e das graves conseqüências que acarreta para a saúde física e mental de nossas pacientes. O médico ginecologista é aquele do qual a mulher espera maior capacidade de apreciar e de tratar seu problema, mas até hoje, a maior parte destes especialistas não tiveram a oportunidade de se preparar para atender as necessidades específicas destas mulheres.

Tanto a Federação Internacional de Ginecologia e Obstetrícia (FIGO) quanto a Federação Latino-Americana (FLASOG) e principalmente a FEBRASGO têm tomado a iniciativa de estimular os colegas a se preocupar com este problema e as instituições de saúde a preparar-se para prestar serviços que respondam às necessidades destas mulheres. Os autores esperam que esta revisão sirva tanto para contribuir a estas iniciativas de nossos órgãos de classe como para informar aos colegas sobre como atuar profissionalmente diante destes casos. 


\section{Referências}

1. United Nations General Assembly. Declaration on the elimination of violence against women. Geneva; 1993.

2. Khan N. Sexual and physical abuse: a threat to reproductive and sexual health. Sex Health Exch. 1998;(1):1-3.

3. Instituto Nacional de Salud Pública. Encuesta Nacional sobre violencia contra las mujeres. Cuernavaca: INSP; 2003.

4. United Nations. Report of the International Conference on Population and Development; 1994 Sep 5-13; Cairo, Egypt. New York: UNO; 1995.

5. United Nations. Report of the 4th World Conference on Women; 1996 Sep 4-15; Beijin, China. New York: UNO; 1996.

6. Coid J, Petruckevitch A, Chung WS, Richardson J, Moorey S, Cotter S, et al. Sexual violence against adult women primary care attenders in east London. Br J Gen Pract. 2003;53(496):858-62.

7. Magid DJ, Houry D, Koepsell TD, Ziller A, Soules MR, Jenny C. The epidemiology of female rape victims who seek immediate medical care: temporal trends in the incidence of sexual assault and acquaintance rape. J Interpers Violence. 2004;19(1):3-12.

8. MacDonald $\mathrm{R}$. Time to talk about rape. BMJ. 2000;321(7268):1034-5.

9. Krug EG, Dahlberg LL, Mercy JA, Zwi AB, Lozano R, editors. World report on violence and health. Geneva: WHO; 2002.

10. Faúndes A, Hardy E, Osis MJ, Duarte G. O risco para queixas ginecológicas e disfunções sexuais segundo história da violência sexual. Rev Bras Ginecol Obstet. 2000;22(3):153-7.

11. Watts C, Zimmerman C. Violence against women: global scope and magnitude. Lancet. 2002;359(9313):1232-7.

12. World Health Organization. Violence against women. Geneva: WHO; 2000.

13. Plichta SB, Falik M. Prevalence of violence and its implications for women's health. Womens Health Issues. 2001;11(3):244-58.

14. Tjaden P, Thoense N. Full report of the prevalence, incidence and consequences of violence against women: findings from the National Violence Against Women Survey. Washington, DC: National Institute of Justice/ United States Department of Justice/Centers for Disease Control and Prevention; 2000. (NIJ 183781).

15. Weiss P, Zverina J. Experiences with sexual aggression within the general population in the Czech Republic. Arch Sex Behav. 1999;28(3):265-9.

16. Bagley C, Bolitho F, Bertrand L. Sexual assault in school, mental health and suicidal behaviors in adolescent women in Canada. Adolescence. 1997;32(126):361-6.

17. Boyer D, Fine D. Sexual abuse as a factor in adolescent pregnancy and child maltreatment. Fam
Plann Perspect. 1992;24(1):4-11, 19.

18. King G, Flisher AJ, Noubary F, Reece R, Marais A, Lombard C. Substance abuse and behavioral correlates of sexual assault among South African adolescents. Child Abuse Negl. 2004;28(6):683-96.

19. Steel-Duncan JC, Pierre R, Evans-Gilbert T, Rodriquez B, Christie CD. HIV/AIDS following sexual assault in Jamaica children and adolescents: a case for HIV post-exposure prophylaxis. West Indian Med J. 2004;53(5):352-5.

20. Abma J, Driscoll A, Moore K. Young women's degree of control over first intercourse: an exploratory analysis. Fam Plan Perspect. 1998;30(1):12-8.

21.Diniz SG, d'Oliveira AF. Gender violence and reproductive health. Int J Gynaecol Obstet. 1998;63 Suppl 1:S33-42.

22. Heise L, Ellsberg M, Gottmoeller M. Ending violence against women. Baltimore: Johns Hopkins University School of Public Health; 1999. (Population Reports, series L, 11).

23. Centro Nacional de Equidad de Género y Salud Reproductiva. Modelo integrado para la prevención y atención de la violencia familiar y sexual. Manual operativo. Guadalajara: Secretaría de Salud; 2004.

24. Dickson N, Paul C, Herbison P, Silva P. First sexual intercourse: age, coercion, and later regrets reported by a birth cohort. BJM. 1998;316(7124):29-33.

25. Cáceres CF, Vanoss Marin B, Sid Hudes E. Sexual coercion among youth and young adults in Lima, Peru. J Adolesc Health. 2000;27(5):361-7.

26. Rivera-Rivera L, Lazcano-Ponce E, Salmeron-Castro J, Salazar-Martínez E, Castro R, Hernández-Avila M. Prevalencia y determinación de la violencia de la pareja contra las mujeres mexicanas: un estudio basado en población. Salud Pública Mex. 2004;46(2):113-22.

27. Slaughter L. Involvement of drugs in sexual assault. J Reprod Med. 2000;45(5):425-30.

28. Drezett J, Caballero M, Juliano Y, Prieto ET, Marques JA, Fernandes CE. Study of mechanisms and factors related to sexual abuse in female children and adolescents. J Pediatr (Rio J). 2001;77(5):413-9.

29. Oshikata CT, Bedone AJ, Faúndes A. Atendimento de emergência a mulheres que sofreram violência sexual: características das mulheres e resultados até seis meses pós-agressão. Cad Saúde Pública. 2005; 21(1):192-9.

30. Heise L, Ellsberg M, Gottmoeller M. A global overview of gender-based violence. Int $\mathrm{J}$ Gynaecol Obstet. 2002;78 Suppl 1:S5-14.

31. World Health Organization. Guidelines for medicolegal care for victims of sexual violence. Geneva: WHO; 2003.

32. Ononge S, Wandabwa J, Kiondo P, Busingye R. Clinical presentation and management of alleged sexually assaulted females at Mulago hospital, Kampala, Uganda. Afr Health Sci. 2005;5(1):50-4.

33. Jones JS, Wynn BN, Kroeze B, Dunnuck C, Rossman L. Comparison of sexual assault by strangers versus 
known assailants in community-base population. Am J Emerg Med. 2004;22(6):454-9.

34.Danielson CK, Holmes MM. Adolescent sexual assault: an update of the literature. Curr Opin Obstet Gynecol. 2004;16(5):383-8.

35. Sugar NF, Fine DN, Eckert LO. Physical injury after sexual assault: findings of a large case series. Am J Obstet Gynecol. 2004;190(1):71-6.

36. Kerr E, Cottee C, Chowdhury R, Jawad R, Welch J. The Haven: a pilot referral centre in London for cases of serious sexual assault. BJOG. 2003;110(3):267-71.

37. Grossin C, Sibille I, Lorin de la Grandmaison G, Banasr A, Brion F, Durigon M. Analysis of 418 cases of sexual assault. Forensic Sci Int 2003;131(2-3):125-30.

38. Riggs N, Houry D, Long G, Markovchick V, Feldhaus KM. Analysis of 1,076 cases of sexual assault. Ann Emerg Med 2000;35(4):358-62.

39. De Bruyn M. La violencia, el embarazo y el aborto. Cuestiones de derechos de la mujer y de salud pública. $2^{\mathrm{a}}$ ed. Chapel Hill: IPAS; 2003.

40. Martin SL, Matza LS, Kupper LL, Thomas JC, Daly $\mathrm{M}$, Cloutier S. Domestic violence and sexually transmitted diseases: the experience of prenatal care patients. Public Health Rep. 1999;114(3):262-8.

41. Holmes MM, Resnick HS, Kilpatrick DG, Best CL. Rape-related pregnancy: estimates and descriptive characteristics from a national sample of women. Am J Obstet Gynecol. 1996;175(2):320-5.

42. Mulugeta E, Kassaye M, Berhane Y. Prevalence and outcomes of sexual violence among high school students. Ethiop Med J. 1998;36(3):167-74.

43. World Health Organization. Safe abortion: technical and policy guidance for health systems. Geneva: WHO; 2003.

44. Faundes A, Andalaft J. Sexual violence against women. The role of gynecology and obstetrics societies in Brazil. Int J Gynaecol Obstet. 2002;78 Suppl 1:S67-73.

45. Faundes A, Leocadio E, Andalaft J. Making legal abortion accessible in Brazil. Reprod Health Matters. 2002;10(19):120-7.

46. Russo N, Denious J. Understanding the relationship of violence against women to unwanted pregnancy and its resolution. In: Beckman L, Harvey M, editors. The new civil war. The psychology, culture and politics of abortion. Washington, DC: The American Psychological Association; 1999. p. 211-34.

47. World Health Organization. Violence against women: a priority health. Geneva: WHO; 1997.

48. McFarlane J, Malecha A, Watson K, Gist J, Batten E, Hall I, et al. Intimate partner sexual assault against women: frequency, health consequences, and treatment outcomes. Obstet Gynecol. 2005;105(1):99-108.

49. Kawsar M, Anfield A, Walters E, McCabe S, Forster GE. Prevalence of sexually transmitted infections and mental health needs of female child and adolescent survivors of rape and sexual assault attending a specialist clinic. Sex Transm Infect. 2004;80(2):138-41.
50. Baldacini I, Drezett J, Miranda SD, Nisida IVV, Caballero M, Barros ACSD, et al. Prevenção de doenças sexualmente transmissiveis em mulheres vítimas de violência sexual: um modelo de profilaxia. Lima: Unión latinoamericana contra las Enfermedades de Transmisión sexual (ULACETS); 1997. p. 90.

51. Drezett J. Aspectos biopsicossociais da violência sexual. Anais da Reunión Internacional Violencia: Ética, Justicia y Salud para la mujer; 2000 ago; Monterrey, México. Cidade: Editora; 2000. p. 164-182.

52. Gostin LO, Lazzarini Z, Alexander D, Brandt AM, Mayer KH, Silverman DC. HIV testing, counseling, and prophylaxis after sexual assault. JAMA. 1994;271(18):1436-44.

53. World Health Organization. Violence against women and HIV/AIDS: setting the search agenda. Geneva: WHO; 2001. (WHO/FCH/GWH/01.08).

54. Lindegren ML, Hanson IC, Hammett TA, Beil J, Fleming PL, Ward JW. Sexual abuse of children: intersection with HIV epidemic. Pediatrics. 1998;102(4):E46.

55. Meel BL. A study on the prevalence of HIVseropositivity among rape survivals in Transkeyi, South Africa. J Clin Forensic Med. 2003;10(2):65-70.

56. Mein JK, Palmer CM, Shand MC, Templeton DJ, Parekh V, Mobbs M, et al. Management of acute adult sexual assault. Med J Aust. 2003;178(5):226-30.

57. Burgess AW, Holmstrom LL. Rape trauma syndrome and posttraumatic stress response. In: Burgess AW, editor. Rape and sexual assault: a research handbook. New York: Garland Publishing; 1985. p. 46-60.

58. Ramos-Lira L, Saltijeral-Mendez MT, RomeroMendoza M, Caballero-Gutierrez MA, MartinezVelez NA. Violencia sexual y problemas asociados en una muestra de usuarias de un centro de salud. Salud Publica Mex. 2001;43(3):182-91.

59. Hegarty K, Gunn J, Chondros P, Small R. Association between depression and abuse by partners of women attending general practice: descriptive, cross sectional survey. BMJ 2004;328(7440):621-4.

60. Felitti VJ, Anda RF, Nordenberg D, Williamson DF, Spitz AM, Edwards V, et al. Relationship of childhood abuse and household dysfunction to many of the leading causes of death in adults. The Adverse Childhood Experiences (ACE) Study. Am J Prev Med. 1998; 14(4):245-58.

61. Walker EA, Gelfand A, Katon WJ, Koss MP, Von Korff M, Bernstein D, et al. Adult health status of women with histories of childhood abuse and neglect. Am J Med. 1999;107(4):332-9.

62. Anteghini M, Fonseca H, Ireland M, Blum RW. Health risk behaviors and associated risk and protective factors among Brazilian adolescents in Santos, Brasil. J Adolesc Health. 2001;28(4):295-302.

63. World Health Organization. STD case management workbook 1. Programme introduction the transmission and control od STD/HIV. Geneva: WHO; 1995. (WHO/GPA/TCO/PMT/95.18A).

64. Schei B. Psycho-social factors in pelvic pain. A controlled study of women living in physically 
abusive relationships. Acta Obstet Gynecol Scand. 1990;69(1):67-71.

65. Champion JD, Piper JM, Holden AE, Shain RN, Perdue S, Korte JE. Relationship of abuse and pelvic inflammatory disease risk behavior in minority adolescents. J Am Acad Nurse Pract. 2005;17(6):234-41.

66. Collett BJ, Cordle CJ, Stewart CR, Jagger C. A comparative study of women with chronic pelvic pain, chronic nonpelvic pain and those with no history of pain attending general practitioners. Br J Obstet Gynaecol. 1998;105(1):87-92.

67. Ministério da Saúde. Norma técnica prevenção e tratamento dos agravos resultantes da violência sexual contra mulheres e adolescentes. $2^{a}$ ed. Brasília: Ministério da Saúde; 2005.

68. Pedrosa L. Atención médica de personas violadas. Guadalajara: Centro Nacional de Equidad de Genero y Salud Reproductiva/CENSIDA/IPAS; 2000.

69. Granados M, Ortiz JD, Campos L, editores. Monterrey Declaration on Domestic and Sexual Violence Against Women. Monterrey: IPAS; 2000.

70. Christian CW, Lavelle JM, De Jong AR, Loiselle J, Brenner L, Joffe M. Forensic evidence findings in prepubertal victims of sexual assault. Pediatrics. 2000;106(1 Pt 1):100-4.

71. Rosas CF, coordenador. Ética em ginecologia e obstetrícia. $3^{a}$ ed. São Paulo: CREMESP; 2004.

72. Faúndes A, Duarte GA, Osis MJD, Bento SF. Normas e procedimentos jurídico-legais para a obtenção do aborto legal nos serviços de saúde no Brasil. Rev Bras Ginecol Obstet. 1997;19(3):171-6.

73. Mancino P, Parlavecchio E, Melluso J, Monti M, Russo $\mathrm{P}$. Introducing colposcopy and vulvovaginoscopy as routine examinations for victims of sexual assault. Clin Exp Obstet Gynecol. 2003;30(1):40-2.

74. Cheng L, Gulmezoglu AM, Oel CJ, Piaggio G, Ezcurra $\mathrm{E}$, Look PF. Interventions for emergency contraception. Cochrane Database Syst Rev. 2004;(3):CD001324.
75. von Hertzen H, Piaggio G, Ding J, Chen J, Song S, Bartfai $G$, et al. Low dose mifepristone and two regimens of levonorgestrel for emergency contraception: a multicentre randomised trial. Lancet. 2002;360(9348):1803-10.

76.ACOG practice patterns. Emergency oral contraception. Number 3, December 1996 (Replaces No. 2, October 1996). American College of Obstetricians and Gynecologists. Int $\mathrm{J}$ Gynaecol Obstet. 1997;56(3):290-7.

77. Gibb AM, McManus T, Forster GE. Should we offer antibiotic prophylaxis post sexual assault? Int J STD AIDS. 2003;14(2):99-102.

78. Rovi S, Shimoni N. Prophylaxis provided to sexual assault victims seen at US emergency departments. J Am Med Womens Assoc. 2002;57(4):204-7.

79. Sexually transmitted diseases treatment guidelines 2002. Centers for Disease Control and Prevention. MMWR Recomm Rep. 2002;51(RR-6):1-78.

80. Myles JE, Bamberger J. Offering prophylaxis following sexual assault. San Francisco: Department of Public Health/The California HIV PEP after Sexual Assault Task Force/The California State Office of AIDS; 2001.

81. Bamberger JD, Waldo CR, Gerberding JL, Katz MH. Postexposure prophylaxis for human immunodeficiency virus (HIV) infection following sexual assault. Am J Med. 1999;106(3):323-6.

82. California Department of Health Services. Offering HIV Post-Exposure Prophylaxis (PEP) following nonoccupational exposures. San Francisco: The California Task Force on Non-Occupational PEP/ California Department of Health Services/Office of AIDS; 2004.

83. Wiebe ER, Comay SE, McGregor M, Ducceschi S. Offering HIV prophylaxis to people who have been sexually assaulted: 16 months' experience in a sexual assault service. CMAJ. 2000;162(5):641-5.

84. Haddad M, Inch C, Glazier RH, Wilkins AL, Urbshott G, Bayoumi A, et al. Patient support and education for promoting adherence to highly active antiretroviral therapy for HIV/AIDS. Cochrane Database Syst Rev. 2005;(2):CD001442. 